\title{
Intervención sostenible de las ruinas del Liceo Enrique Molina Garmendia en el marco del Plan Concepción 2030
}

\author{
doi: 10.33264/rpa.202001-08 \\ Luis Rolando Rojas Morales \\ Profesor de Taller de Patrimonio y docente de apoyo académico \\ Facultad de Arquitectura, Diseño y Artes Visuales UNIACC
}

\section{Resumen}

Con el tiempo, como sociedad hemos avanzado en considerar al patrimonio cultural como un elemento relevante dentro del desarrollo urbano. En consecuencia, desde la academia lo consideramos como insoslayable dentro de la formación de los nuevos arquitectos. Es por ello que en el marco de una colaboración entre la llustre Municipalidad de Concepción y la Escuela de Arquitectura UNIACC realizada en el año 2019, distintos talleres abordaron encargos pertenecientes a una cartera de proyectos definidos por el municipio y los habitantes de la ciudad en un proyecto de planificación indicativa para la ciudad de Concepción desarrollado en 2014. El Taller de patrimonio de la Escuela de Arquitectura UNIACC asumió como ejercicio académico, la intervención y puesta en valor de las ruinas del ex teatro o salón de actos del Liceo Enrique Molina Garmendia. Así, los alumnos generaron propuestas de arquitectura en el marco de acciones de desarrollo sostenible, considerando la conservación y potenciamiento de los valores patrimoniales del edificio, para proyectar estrategias con las cuales devolverlo a la comunidad en miras al año 2030.

Palabras clave: patrimonio, sostenibilidad, arquitectura, Concepción, docencia.

\section{Abstract}

Over time, as a society we have made progress in considering cultural heritage as a relevant element in urban development. Consequently, from the academy we consider it as unavoidable within the training of new architects. In this context, a plan of collaboration between the Municipality of Concepción and the School of Architecture UNIACC was carried out in 2019, where different workshops addressed commissions belonging to a portfolio of projects defined by the municipality and the inhabitants of the city in a planning project for the city of Concepción developed in 2014. The Heritage Workshop of UNIACC School of Architecture took on the intervention and enhancement of the ruins of Enrique Molina Garmendia High School former theater or auditorium as an academic exercise. Thus, the students generated several architectural suggestions within the framework of sustainable development actions, considering the conservation and enhancement of the building's heritage 
values, to project strategies to return it to the community in 2030.

Keywords: heritage, sustainability, architecture, Concepción, teaching

\section{Plan Concepción 2030, instancia de colaboración entre la Municipalidad de Concepción y la Escuela de Arquitectura UNIACC}

En los últimos años, la ciudad de Concepción ha presentado importantes cambios, entre los que destaca la llegada de nuevas actividades, proliferación de edificios en altura y urbanización de nuevas áreas, todos los cuales no necesariamente han seguido una dirección de desarrollo previamente acordado con la ciudadanía. Por esto, en base al Plan de desarrollo comunal, el municipio definió en el año 2014, el desarrollo del proyecto Trabajando Concepción, una nueva ciudad al 2030, el cual define de manera indicativa, cuatro ejes de desarrollo; Concepción como ciudad universitaria-cultural, ciudad prestadora de servicios, ciudad deportiva y ciudad turística (Ilustre Municipalidad de Concepción, 2014). Dentro de la cartera de proyectos correspondientes al eje ciudad universitaria-cultural, se definió la ejecución de las obras de recuperación del ex teatro o salón de actos del Liceo Enrique Molina (1), así como la construcción de centros culturales, centros deportivos y recreativos, entre muchos otros proyectos correspondientes a los distintos ejes del Plan.

Como parte del proceso continuo de vinculación con el medio que efectúa la Facultad de Arquitectura, Diseño y Artes Visuales de la Universidad UNIACC, se estableció durante 2019, la firma de un convenio de colaboración interinstitucional, en el cual, distintos talleres de arquitectura desarrollarían de manera académica el diseño de algunos proyectos arquitectónicos visualizados por el municipio de cara al 2030. De esta manera nace Concepción 2030 (2), instancia en la que el Taller VII de patrimonio abordó la recuperación de las ruinas del ex Teatro Liceo Enrique Molina, -ubicadas en el área urbana, junto al Parque Ecuador-, proyectándolo como un nuevo Centro de Desarrollo Social y Comunitario para la ciudad, abordándolo como un desafío de intervención arquitectónica patrimonial en el marco de acciones de desarrollo sostenible.

En el año 2018, como parte de un convenio firmado entre la Facultad y la llustre Municipalidad de Providencia, se desarrolló el plan Providencia 2030, el cual desarrollado por los distintos talleres de la facultad, incorporó proyectos vinculados al patrimonio cultural de la comuna, como los Tajamares del Río Mapocho, recuperación de cités, Mercado el Aguilucho, entre muchos otros (UNIACC, 2018), inaugurando la celebración de este tipo de convenios inter-institucionales en que la Facultad aporta desde su visión particular de enseñanza vinculada a la comunicación 
y uso innovador de la tecnología.

Imagen 1. Fotografía aérea tomada mediante drone del sitio patrimonial y su contexto en el centro de la ciudad de Concepción.

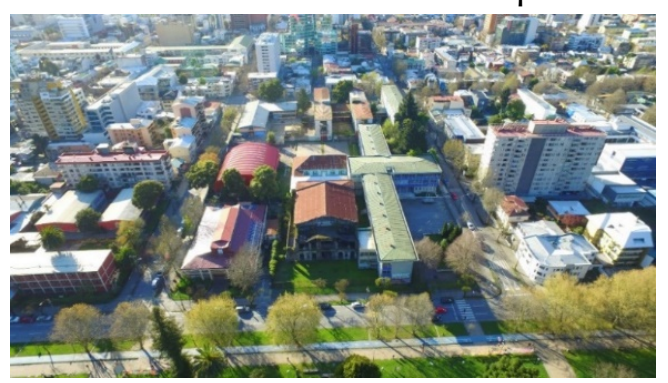

Fuente: Felipe Araya.

\section{El lugar del legado cultural en la enseñanza de la arquitectura. Séptima versión del taller de patrimonio UNIACC}

Diversos documentos nacionales e internacionales remarcan la importancia de considerar al patrimonio como parte integral del desarrollo urbano y de los procesos de formación en las nuevas generaciones de arquitectos.

A nivel nacional, en la Política Nacional de Desarrollo Urbano, Ciudades Sustentables y Calidad de Vida (2014), se reconoce "la responsabilidad del Estado y de los ciudadanos respecto del resguardo, mantención, puesta en valor y difusión del patrimonio cultural, en tanto bien social que beneficia a los ciudadanos" (2014:21). Así también, la política promueve su registro y valoración por cuanto se reconoce su aporte en la generación de valor social que beneficia y fortalece la identidad de las comunidades. Finalmente, como un ámbito relevante de cómo convivir con el legado cultural, reconoce que el patrimonio puede ser intervenido para adaptarlo a nuevas necesidades, incorporando nuevos usos y tecnologías las cuales sean capaces de agregarle valor. Hoy se encuentra en tramitación la nueva ley de patrimonio de Chile, la cual busca actualizar la normativa asociada al patrimonio con respecto a la doctrina internacional, promoviendo la toma de decisiones a nivel local, para facilitar intervenciones y planes de gestión, comprendiendo la protección del patrimonio como un proceso dinámico, el que es necesario llevar a cabo acciones como conocer, valorar, proteger, conservar, difundir y gestionar (Subsecretaría del Patrimonio Cultural, 2019).

Con respecto a los nuevos arquitectos, -en lo internacional-, la carta Unesco/UIA de la formación en arquitectura (2011), en su breve extensión, menciona seis veces al patrimonio cultural, reconociéndolo como un asunto de interés público al cual la arquitectura debe responder de manera responsable y armoniosa en su integración, logrando por medio de la formación universitaria integrar estos fines, propone una 
busqueda de comprensión por parte de los alumnos de la noción de patrimonio cultural en los distintos contextos y entornos construidos. Por esto, la actual malla de la Facultad de arquitectura considera dos cursos relacionados a la temática del patrimonio cultural arquitectónico, otorgándole un enfoque innovador vinculado al uso de la tecnología.

En Chile existen un total de 1.528 monumentos históricos y 146 zonas típicas, protegidos por la Ley de Monumentos (Consejo de Monumentos Nacionales, 2020), sumado a 3.683 inmuebles de conservación histórica y 235 zonas de conservación histórica (Minvu) protegidas a través de los distintos planes reguladores de las ciudades del país. Algunos de ellos han sido intervenidos para ser habilitados y prestar un servicio a la sociedad, destacando casos como el Palacio Pereira, Palacio de La Moneda, Museo de Arte Precolombino y nuevo edificio de la Facultad de Artes UC., los cuales han sido transformados como parte de una estrategia de conservación patrimonial (Pérez \& Pérez, 2018).

Importantes concursos nacionales e internacionales han considerado preexistencias patrimoniales ubicadas a lo largo de las distintas regiones del país, como piezas clave de estrategias proyectuales contenidas en planes maestros urbanos. Ante esta relevancia y vigencia del desarrollo de estas acciones dentro del quehacer profesional de los arquitectos, el Taller VII de patrimonio considera también la revisión de cartas y documentos internacionales referidos a acuerdos colectivos sobre el tratamiento del patrimonio en sus distintas dimensiones.

El Taller VII de patrimonio busca además establecer grados de vinculación con comunidades y sus necesidades sociales vinculadas a conjuntos e inmuebles, muchas veces subutilizados, abandonados o en estado de ruinas, celebrando ya siete versiones desde el año 2016. Ha abordado principalmente inmuebles que forman parte del patrimonio industrial de la ciudad, como los galpones de Chucre Manzur en Providencia, inmuebles de barrios obreros en Santiago y Estación Central, Gimnasio Ferroviario y Teatro Municipal de San Bernardo, entre muchos otros. 


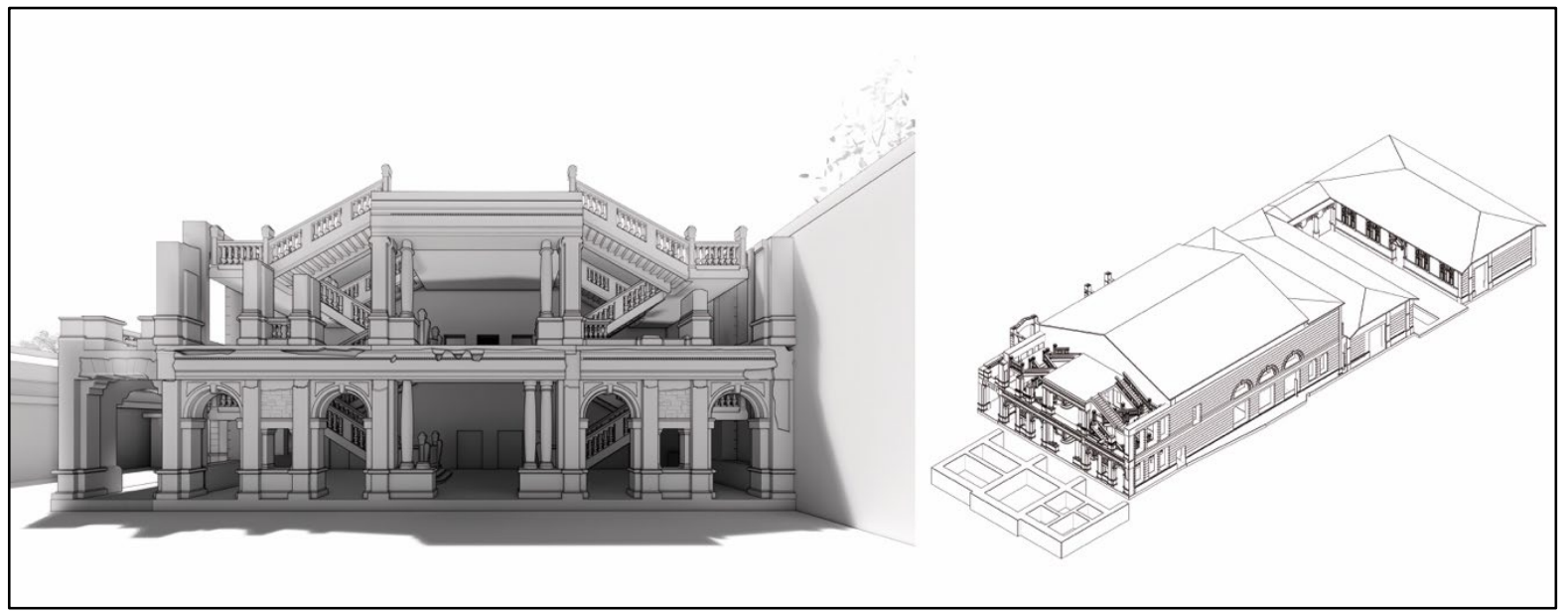

Fuente: UNIACC.

\section{Las Ruinas del Teatro Enrique Molina como oportunidad para proponer intervenciones patrimoniales sustentables}

El crecimiento de las ciudades en población y extensión nos llevan a pensar el rol del patrimonio cultural arquitectónico en la ciudad, considerándolo ya no como un objeto de mera observación, sino como una oportunidad para la generación de distintos tipos de desarrollo. En este sentido, se torna importante intervenir el patrimonio habilitándolo para satisfacer necesidades mediante la acción del sector público o privado en un contexto de toma de decisiones responsables e informadas. El Taller posee un enfoque teórico de intervención patrimonial sostenible. La sostenibilidad asociada al patrimonio cultural arquitectónico se vincula a acciones llevadas a cabo por arquitectos, las cuales son capaces conservar los valores patrimoniales que los bienes culturales arquitectónicos detentan tras llevar a cabo las operaciones de ampliación, restauración, reconstrucción y demolición parcial en el proceso de reutilización de un bien arquitectónico patrimonial. Cada una de manera independiente o mediante la combinación de más de una de ellas en una determinada obra.

De esta manera, el Taller asume -como doctrina-, mediante el análisis histórico, arquitectónico, urbano y social el definir criterios que permitan que estos valores perduren en el tiempo contribuyendo que las futuras generaciones puedan disfrutar de los mismos y logrando en base a ellos, satisfacer también, sus propias necesidades. Como parte del encargo que dio paso al proceso proyectual del taller durante el año 2019, los estudiantes se organizaron en cuatro grupos los cuales abordaron distintas dimensiones atingentes al ex teatro y su entorno; estudio histórico, modelado BIM 
de la preexistencia en base al levantamiento crítico entregado por el municipio, estudio urbano y arquitectónico. Luego, la combinación de participantes de cada uno de los equipos permitió definir valores patrimoniales presentes en el edificio, importantes de ser conservados tras la futura intervención. Los alumnos de manera individual, presentaron una propuesta de criterios de intervención, logrando diversas posturas y ubicaciones del programa necesario para el nuevo Centro de Desarrollo Social y Comunitario con respecto a la ruina. A veces, demoliendo algunos elementos, en otras oportunidades ampliando mediante la edificación de nuevos volúmenes, reconstruyendo zonas derruidas con el tiempo y restaurando otras.

Imágenes 4 y 5 . Esquematización de algunos de los criterios de intervención propuestos por los alumnos para la recuperación de las Ruinas del Teatro Enrique Molina.

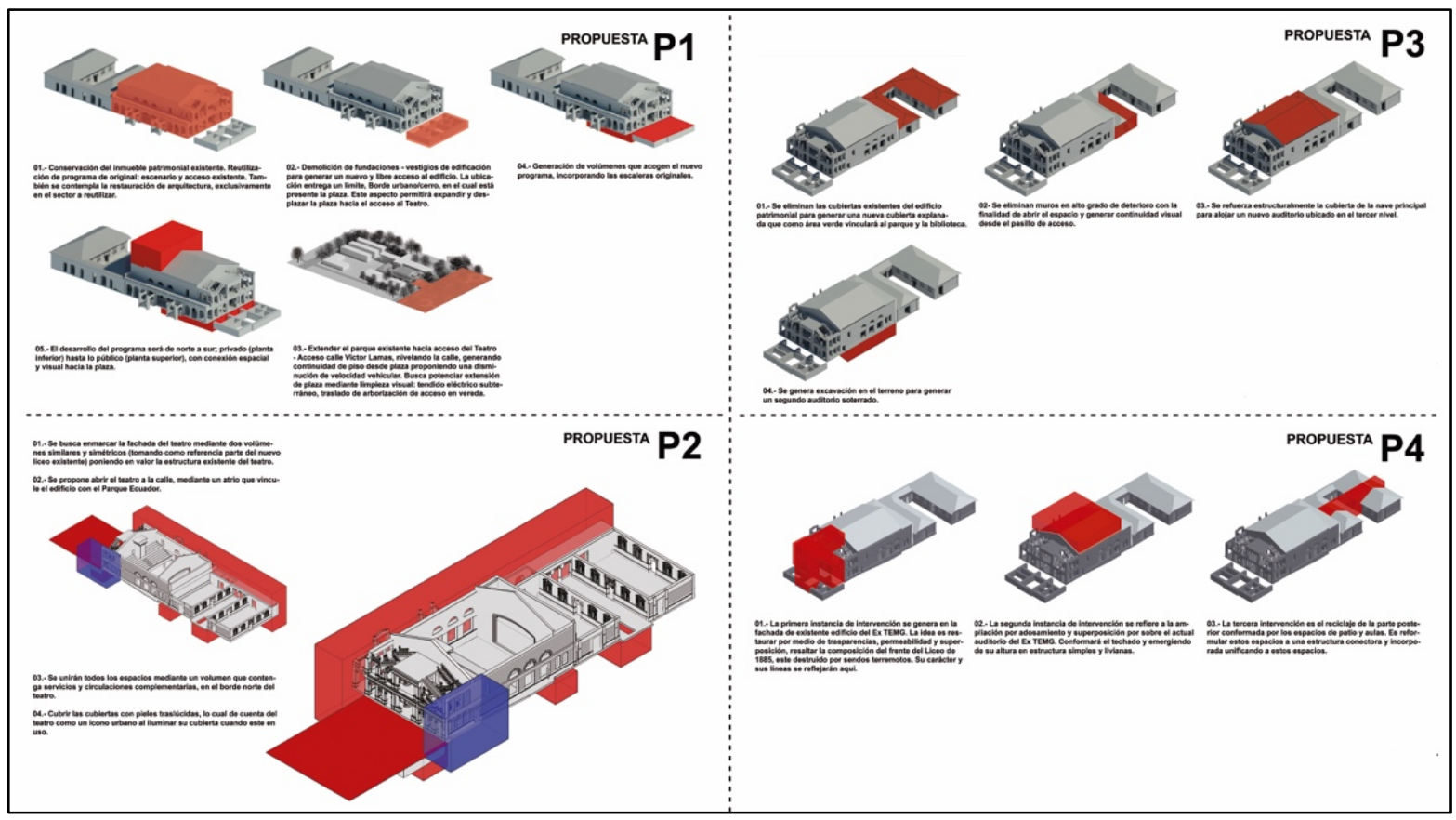

Fuente: UNIACC.

Dentro de las propuestas destacadas, se encuentra la de Agueda López, quien realiza un estudio geométrico de la estructura del antiguo teatro, para plantear una nueva estructura que intenta integrarse a los elementos preexistentes posibilitando una lectura unitaria. La propuesta de Caleb Vallejos planteó la restauración de la fachada de la ruina y la construcción de una nueva sala con cubierta habitable. Carol Sánchez proyectó un volumen anterior a la fachada, el cual ilumina y deja ver hacia el exterior el antiguo edificio, conformando un hall de acceso a las nuevas instalaciones. Los alumnos Felipe Araya y Jessica Soto, propusieron como criterio general de intervención, añadir un nuevo volumen longitudinal en el costado sur del terreno, alojando parte del programa y generando una nueva circulación como forma de recorrer y contemplar el edificio histórico. 
Imágenes 6 y 7. Propuesta de intervención en base a una nueva estructura que intenta integrarse a los elementos preexistentes posibilitando una lectura unitaria.
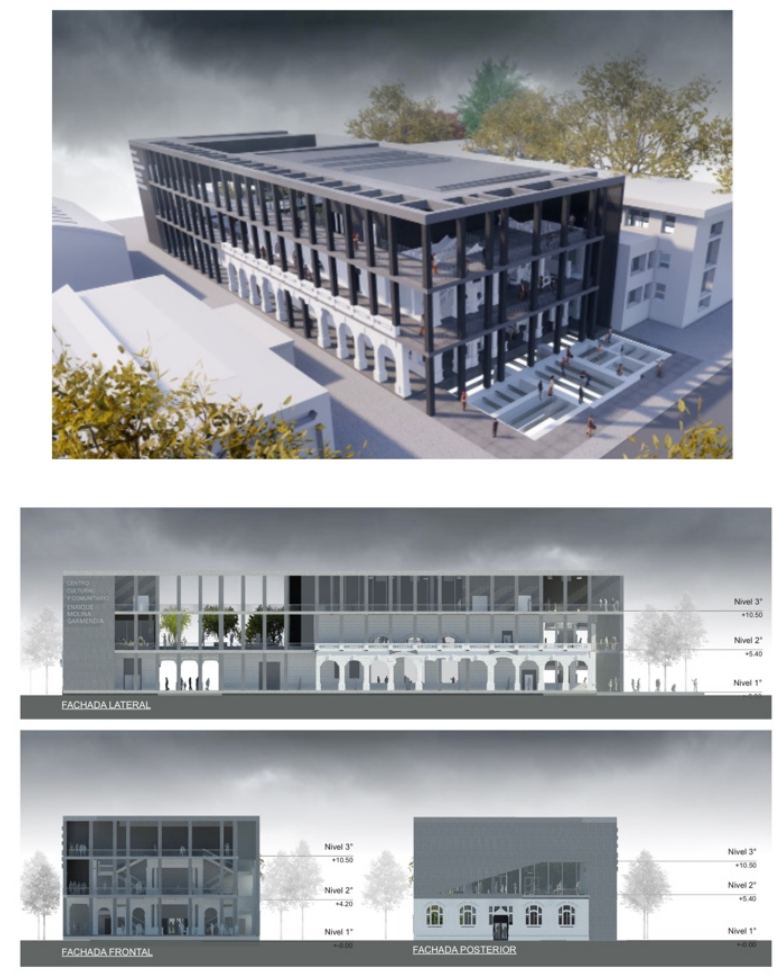

Fuente: Agueda López.

En tres propuestas desarrolladas por los alumnos, se reconocen las fundaciones del edificio del liceo demolido por el terremoto y que hoy se encuentran ubicadas entre las ruinas y la calle Víctor Lamas, planteando en algunos casos un museo subterráneo y en otros, un espacio público patrimonial en que los vestigios estructurales del edificio quedaban a la vista de los visitantes.

Imágenes 8 y 9. Vista vuelo de pájaro y tratamiento de la fachada de algunas propuestas desarrolladas en el taller.

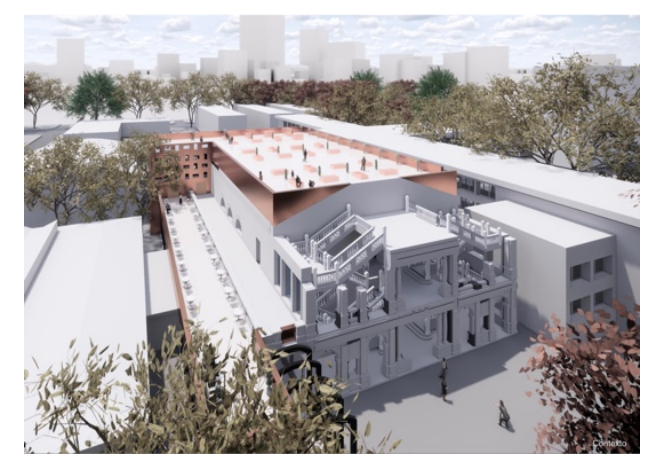




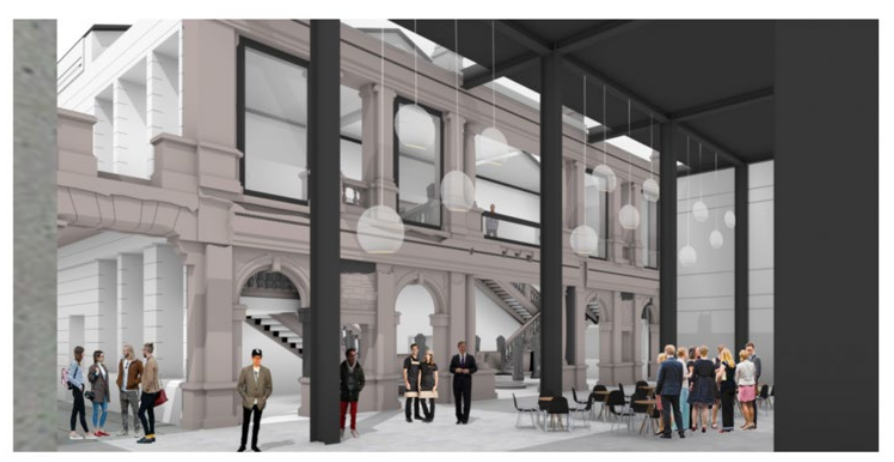

Fuente: Caleb Vallejos y Carol Sánchez.

Debido a la variedad de propuestas desarrolladas de manera individual por los diecinueve alumnos del taller (3), las alternativas presentadas de criterios de intervención observables fueron diversas, existiendo aquellas en que por ejemplo; se conservaba el estado de ruina del edificio, se optó por restaurar parcialmente el edificio existente. En otras propuestas se añaden nuevos volúmenes ubicados en la zona superior, lateral o inferior, de manera vertical o longitudinal, se demuelen algunas estructuras y se reconstruyen otras en base a los planos existentes del edificio original, todas las cuales permitían dar espacio al programa cultural que forma parte del encargo Centro de Desarrollo Social y Comunitario.

En definitiva, lo común a todas las propuestas, es que plantean revitalizar el antiguo salón de actos, planteando la incorporación de arquitectura contemporánea diferenciable de la arquitectura histórica del edificio, buscando una integración de obras de arquitectura representativa de distintos momentos de la historia. Se busca dotar a los futuros arquitectos de bases conceptuales y aprendizajes procedimentales los cuales sean útiles en el ejercicio público y privado de la profesión, los cuales pueden ser profundizados mediante estudios posteriores de postgrado. Conviene apuntar que la continuidad de este curso se desarrolla a través de un programa de magister diseñado al interior de la facultad, con el objetivo de profundizar en los ámbitos de la sostenibilidad y la proyección y ejecución de propuestas de arquitectura y urbanismo asociada al patrimonio cultural. Una necesidad cada vez más urgente, buscando aportar a la generación de un cambio de conciencia por parte de los futuros profesionales, hacia los bienes patrimoniales que son testimonio de la historia de nuestra sociedad.

Parte de los resultados parciales de este taller fueron expuestos como parte de la muestra de escuelas de arquitectura de la XXI Bienal de Arquitectura de Chile, como parte del evento Plan Concepción 2030, celebrado en el mes de octubre de 2019, en dependencias del antiguo Mercado Franklin en la comuna de Santiago, el cual contó con la presencia de representantes de la Municipalidad de Concepción, estableciendo un diálogo en torno al presente y futuro de la ciudad y su patrimonio. 
Imágenes 10, 11 y 12. Presentación final de maquetas y láminas de exámen de finalización del taller de patrimonio en su versión 2019.

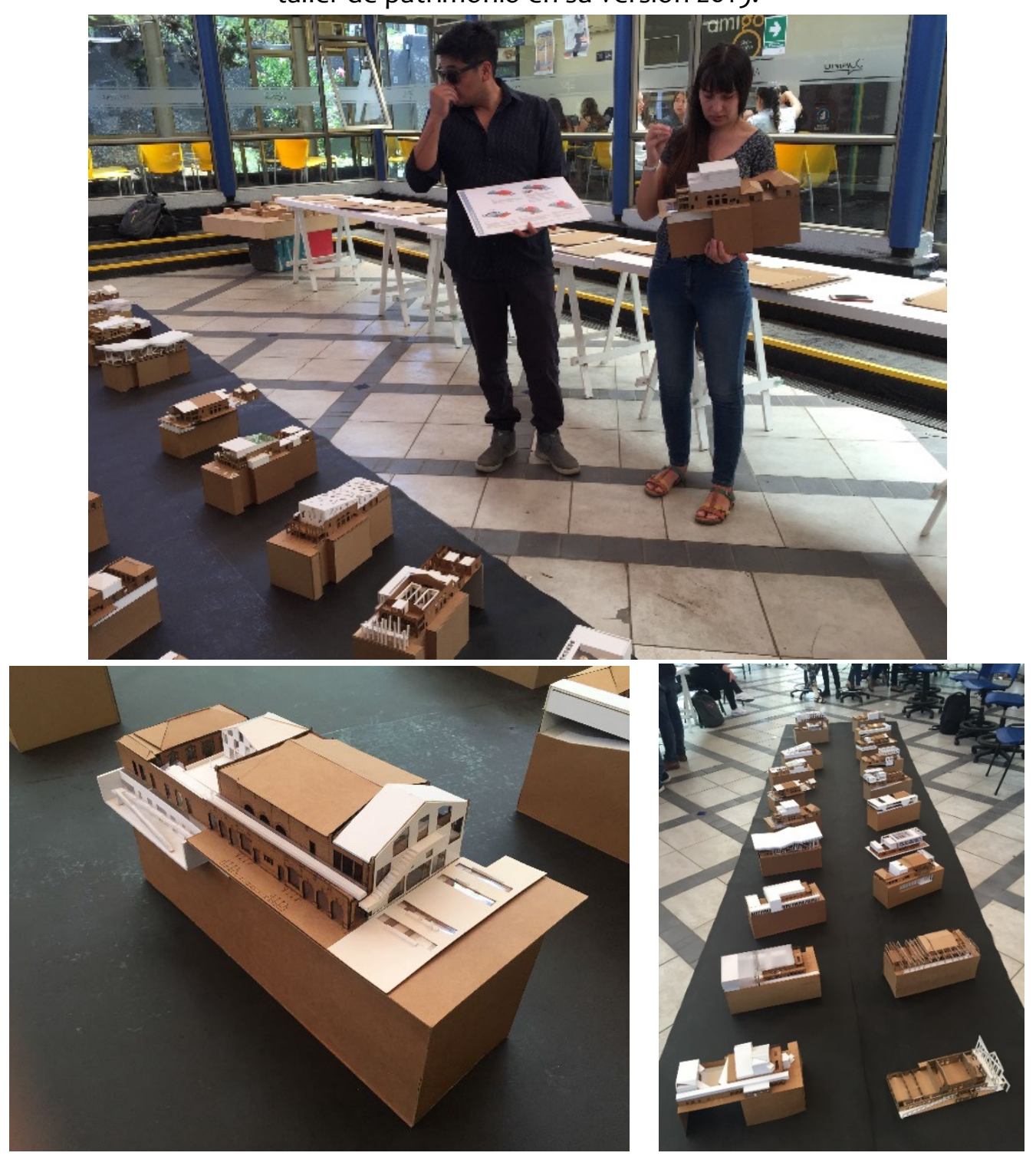

Fuente: UNIACC (2019).

\section{Notas}

(1) El edificio del Liceo Enrique Molina Garmendia fue diseñado por el arquitecto Onofre Montané Urrejola y construido en el año 1920, siendo destruido por el terremoto de 1960. El proyecto original contemplaba la construcción de la totalidad de la manzana no siendo completado. Entre 1929 y 1935 se construyó el teatro o salón de eventos, el cual rodeado de dos patios laterales, se ubicaba tras la torre principal del edificio educacional. Hoy se conservan las fundaciones del edificio frontal, las cuales se encuentran en el antejardín de las ruinas del teatro. (2) Participaron en la gestión del Plan Concepción 2030 desde la Facultad de Arquitectura UNIACC, Humberto Toro, Juan Luis Ramírez, José Luis Barrientos, Absalón Fuentes, Martha Hernández, Nicolás Li Calzi, Hugo Peña, Martín Durán, Cesar Ascencio y Luis Rojas.

(3) Los alumnos participantes desde el Taller VII fueron Agueda López, Braulio Gálvez, Caleb Vallejos, Camila Novoa, Christian Amaro, Claudio mella, Carol Sánchez, Eugenio Medina, Ezequiel Acuña, Felipe Araya, Felipe Maturana, Fernando Montano, Jessica Soto, Jesé Luis Molina, Laura Gálvez, Lita Ibarra, Ricardo Gaita, Rosa Inda y Víctor Ancavil. El equipo docente estuvo conformado por Luis Rojas y Natalia Pérez. 


\section{Referencias}

Consejo de Monumentos Nacionales (2020). Monumentos Nacionales por decreto a Enero de 2020. https://www.monumentos.gob.cl/

Ilustre Municipalidad de Concepción (2014). Trabajando Concepción, una nueva ciudad al 2030. https://www.concepcion.cl/wp-content/uploads/2015/02/plan-20-30.pdf

Ley de Monumentos Nacionales 17.288.

http://www.uta.cl/masma/patri_edu/PDF/LeyMonumentos.PDF

Minvu. Sitio web Patrimonio Urbano: inmuebles y zonas patrimoniales. https://www.patrimoniourbano.cl/

Ordenanza General de Urbanismo y Construcciones (OGUC). (2012). http://www.minvu.cl

Pérez, O. \& Pérez E. (2018). El Patrimonio y sus desafíos contemporáneos. Comprender, proteger, transformar. En Estudios Patrimoniales. José de Nordenflycht editor. Ediciones UC.

Política Nacional de Desarrollo Urbano, Ciudades Sustentables y Calidad de Vida (2014). http://www.mtt.gob.cl/wp-content/uploads/2014/03/Pol\%C3\%ADtica-Nacionalde-Desarrollo-Urbano-2013.pdf

Subsecretaría del Patrimonio Cultural (2019). Minuta Ley Patrimonio 2019. Documento.

UNESCO \& UIA (2011). Carta UNESCO / UIA de la formación en arquitectura, Tokio.

Universidad UNIACC (2018). Blog de la universidad UNIACC. https://www.uniacc.cl/2018/06/alumnos-de-escuela-de-arquitectura-de-universidaduniacc-compartieron-vision-academica-sobre-barrio-el-aguilucho/

\section{Luis Rolando Rojas Morales}

Arquitecto Universidad Central de Chile. Magister en Desarrollo Urbano IEUT UC y Diplomado en Patrimonio Cultural UC y Diplomado en Gerencia Pública U. de Chile. Profesor de Taller de Patrimonio y docente de apoyo académico Escuela de Arquitectura UNIACC. Email: luis.rojas.morales@uniacc.edu 